\title{
Angiogenic characteristics of circulating and tumoural thrombospondin-1 in breast cancer
}

\author{
G.J. BYRNE ${ }^{1}$, K.E.HAYDEN ${ }^{2}$, G. McDOWELL ${ }^{3}$, H. LANG ${ }^{1}$, C.C. KIRWAN ${ }^{1}$, \\ L. TETLOW ${ }^{2}$, S. KUMAR ${ }^{4}$ and N.J. BUNDRED ${ }^{1}$
}

\begin{abstract}
Departments of ${ }^{1}$ Surgery and ${ }^{2}$ Biochemistry. South Manchester University Hospitals, Wythenshawe Hospital, Southmoor Road, Manchester, M23 9LT; ${ }^{3}$ Department of Clinical Biochemistry, Central Manchester and Manchester Childrens Hospital NHS Trust, Manchester Royal Infirmary, Oxford Road, Manchester, M13 9WL; ${ }^{4}$ Division of Laboratory and Regenerative Medicine, Medical School, University of Manchester and Christie Hospital Manchester, M13 9PL, UK
\end{abstract}

Received May 24, 2007; Accepted July 12, 2007

\begin{abstract}
In cancer models, thrombospondin-1 (TSP-1) has been shown to inhibit angiogenesis or promote metastasis by increasing adhesion of malignant cells to endothelium. To determine the role of TSP-1 in breast cancer and breast cancer angiogenesis, we have measured TSP-1 in plasma and tumour cytosols and compared levels to established clinicopathological prognostic parameters and intratumoural microvessel density. TSP-1 was measured, by radioimmunoassay, in plasma (pTSP-1) and tumour cytosols (cTSP-1) of women with early breast cancer (EBC) $(n=71)$. pTSP-1 in EBC was compared to pTSP-1 levels in women with advanced breast cancer (ABC) $(n=66)$, normal controls $(n=77)$ and was correlated with prognostic features and microvessel density (MVD) (measured by CD31 immunostaining). cTSP-1 levels were compared to prognostic features and microvessel density. pTSP-1 in women with EBC (median 484, IQR 344-877 $\mathrm{ng} / \mathrm{ml}$ ) and ABC (median 588, IQR 430-952 ng/ml) were elevated when compared to normal controls (median 21, IQR 175-247) $(\mathrm{p}<0.001)$. Women with lymph node metastases $(n=35)$ had higher levels of TSP-1 (median $799 \mathrm{ng} / \mathrm{ml}$, IQR 455-943) than women who were node negative (median $343 \mathrm{ng} / \mathrm{ml}$, IQR 267-514) $(\mathrm{n}=36)(\mathrm{p}<0.05)$. Levels of pTSP-1 in EBC correlated with MVD $(\mathrm{R}=0.39, \mathrm{p}<0.05)$. Levels of TSP-1 in tumour cytosols of women with EBC (median 1714, IQR $893-5283 \mathrm{ng} / \mathrm{ml}$ ) correlated with microvessel density $(\mathrm{R}=0.46$, $\mathrm{p}<0.01)$. Circulating levels of TSP-1 appear to be a marker of breast cancer aggressiveness and in breast cancer may have a pro-angiogenic rather than anti-angiogenic role.
\end{abstract}

Correspondence to: Dr G. McDowell, Department of Clinical Biochemistry, Manchester Royal Infirmary, Oxford Road, Manchester, M13 9WL, UK

E-mail: garry.mcdowell@manchester.ac.uk

Key words: angiogenesis, breast cancer, tumour marker

\section{Introduction}

Thrombospondin (TSP-1) is a high molecular weight glycoprotein, originally described as secretion product of platelets (1), which functions as an adhesive protein in cell-cell and cell-substratum interactions. TSP-1 is a multifunctional protein with several isoforms (2-4). Following synthesis by endothelial cells, TSP-1 is incorporated into the extra-cellular matrix of these cells (5).

The metastatic spread of cancer is a complex and multistep process characterised by a number of biological functions. These include the arrest and adhesion of circulating tumour cells in the vascular bed, invasion of tumour cells through the basement membrane and growth of new tumour colonies in the organ parenchyma. Several cell lines secrete TSP-1 including melanoma, fibrosarcoma and carcinoma (6). The presence of TSP-1 has been shown to promote the adhesion and spread of melanoma cells in vitro $(7,8)$. TSP-1 has been shown to cause a dose-dependent stimulation of tumour cell invasion of collagen in vitro using oral squamous carcinoma cells (9) and TSP-1 injected intravenously with mouse sarcoma cells, greatly potentiates lung colony formation (10). Moreover, in the presence of TSP-1, MCF-7 breast carcinoma cells attach to human endothelial cells and form tumour cell aggregates (11). Thus TSP-1 appears to have a crucial role in the haematogenous spread of solid tumours.

TSP-1 is overexpressed in breast cancer tissue when compared to normal breast tissue (12-14) but there is controversy as to the exact biological function of TSP-1. Some studies suggest that TSP-1 is an inhibitor of angiogenesis $(15,16)$, whilst others have suggested that TSP-1 promotes neovascularisation $(17,18)$. The reason for the conflicting evidence is unclear but clarification of the biological functions of TSP-1 in malignancy may lead to advances in therapeutic strategies for the retardation of tumour angiogenesis and metastasis.

Although TSP-1 is a secretion product of platelets (1) that is released into the serum following routine phlebotomy $(19,20)$, extra-platelet sources are known to contribute to circulating TSP-1 $(21,22)$.

We have recently described a radioimmunoassay for the measurement of background circulating levels of TSP-1 in 
plasma (23). Using similar assays, several small studies have shown increased levels of plasma TSP-1 in gynaecological malignancies (24), colorectal carcinoma (25) and acute myeloblastic leukaemias (26) when compared to normal controls. In addition, in colorectal carcinoma, levels of plasma TSP-1 correlate with tumour stage (25).

The aim of this study was to clarify the role of TSP-1 in breast cancer angiogenesis and metastasis by measuring levels of TSP-1 in tumour cytosols and plasma of women with breast cancer.

\section{Materials and methods}

Patients with early breast cancer were recruited from a breast clinic at South Manchester University Hospitals Trust, UK and patients with advanced breast cancer were recruited from a breast oncology clinic at the same hospital. These studies were approved by the South Manchester Local Ethics Committee. All subjects gave written informed consent.

Patients with early breast cancer. Women with newly diagnosed EBC $(n=71)$ provided venous blood immediately prior to surgery (Axillary lymph node clearance with either mastectomy or wide local excision). The mean age at diagnosis was 56.4 years (range 33-89 years). Twenty-seven of the women were premenopausal at the time of diagnosis whilst 44 were postmenopausal. Following surgery, the excised primary specimens were incised and a 1-3 g wedge biopsy was removed from the primary tumour and snap-frozen in liquid nitrogen. The remainder of the specimen and the excised axillary nodes were immersed in formalin for $12 \mathrm{~h}$ and then serial sections were embedded in paraffin blocks and sent for histological examination. An experienced breast pathologist assessed haematoxylin-eosin stained specimens for tumour type, size and grade without knowledge of plasma or intratumoural levels of TSP-1 or CD31. The number of nodes in the axillary clearance specimens and the total number of involved nodes were recorded for each patient.

Early breast cancer control group. Blood was also taken from a control group of 36 women who had attended the same clinic with benign breast disease. For tumour cytosol work, nine women who underwent excision biopsy for benign breast disease had a 3 -g piece of normal breast tissue excised.

Patients with advanced breast cancer. Plasma samples were taken from 66 women with advanced breast cancer. All of the women had evidence of metastatic disease in the skeleton, as diagnosed by isotope bone scan and plain radiographs. The mean age of women with $\mathrm{ABC}$ was 57.3 years (range 4178 years).

Advanced breast cancer control group. A separate control group of women was recruited for analysis of plasma TSP-1 levels in $\mathrm{ABC}$. These women $(n=41)$ had previously undergone surgery for primary breast cancer but had no radiological or clinical evidence of metastatic disease.

Blood sampling. Plasma was prepared in such a way as to prevent contamination from activated platelets by a method we have previously described (23) and tumoural and plasma thrombospondin was measured using radioimmunoassay.
Preparation of tissue cytosols. Twenty $\mu 1$ of $2 \mathrm{mg} / \mathrm{ml}$ leupeptin, $20 \mu 11 \mathrm{mg} / \mathrm{ml}$ aprotinin, $20 \mu 11 \mathrm{mg} / \mathrm{ml}$ pepstatin A, $50 \mu 1200 \mathrm{mM}$ PMSF, $50 \mu 1100 \mathrm{mM}$ benzamidine were added to $10 \mathrm{ml}$ of RIPA buffer in a plastic tube.

A sample of tumour, approximately the size of $500 \mathrm{mg}$, was separated out into a mortar, cut into thin slices and crushed using a porcelain pestle. This was repeated until only fine grains of sample were remaining. The sample was transferred to a pre-weighed tube, and weighed. Protease inhibitor solution was added in an amount (in $\mathrm{ml}$ ), 10 times the weight of tumour ( $\mathrm{g}$ ), and the mixture was finely mixed and any large grains broken up using a homogeniser. NP 40 was then added in an amount that was 1/100th of the volume of buffer that was added. (i.e. 1/10th of the mass of the tumour sample, in $\mathrm{ml}$ ) and the samples then placed onto a mechanical wheel for at least an hour. Samples were centrifuged at $15000 \mathrm{~g}$ at $4^{\circ} \mathrm{C}$ for $10 \mathrm{~min}$. The supernatant was carefully transferred into Ependorfs, which were then stored at $-70^{\circ} \mathrm{C}$

Radioimmunoassay for thrombospondin. Assay buffer of $0.05 \mathrm{M}$ phosphate buffer $\mathrm{pH} 7.4$ containing $2 \%$ horse serum (Harlan Sera-Lab, Sussex, UK) and 1\% Tween-20 was prepared fresh daily. Wash solution was prepared containing $0.9 \%$ $\mathrm{NaCl}$ and $0.05 \%$ Tween-20. Standards were prepared from purified thrombospondin $(1 \mathrm{mg} / \mathrm{ml})$ (Cabiochem, Nottingham, UK) to give a range of concentrations from $0-1000 \mathrm{ng} / \mathrm{ml}$ in assay buffer.

Thrombospondin was iodinated using a modification of the technique of Greenwood and Glover (27). Thrombospondin $(10 \mu \mathrm{l})$ was incubated for $60 \mathrm{sec}$ with $0.5 \mathrm{mCi} \mathrm{Na}{ }^{125} \mathrm{I}$ (Amersham International, Amersham, UK) and $10 \mu 1$ chloramine $\mathrm{T}(5 \mathrm{mg} / \mathrm{ml}$ in $0.05 \mathrm{M}$ phosphate buffer, $\mathrm{pH} 7.4)$. The reaction was stopped by adding $20 \mu \mathrm{l}$ sodium metabisulphite $(5 \mathrm{mg} / \mathrm{ml}$ in $0.05 \mathrm{M}$ phosphate buffer, $\mathrm{pH} 7.4$ ) and $350 \mu \mathrm{KI}(0.1 \%$ in $0.05 \mathrm{M}$ phosphate buffer, $\mathrm{pH} 7.4)$. The iodinated product was purified by gel filtration using a Sephadex G-100 column (16 mm x $40 \mathrm{~cm}$ ) equilibrated by assay buffer. Specific activities of $35 \mu \mathrm{Ci} / \mu \mathrm{g}$ were routinely achieved with $\sim 70 \%$ transfer.

Thrombospondin was measured by competitive radioimmunoassay using a modification of the method used by Dawes and Gogstad (3). The concentration of reagents was optimised so that a $50 \mu 1$ sample in duplicate was added to $200 \mu 1$ of ${ }^{125} \mathrm{I}$-thrombospondin and $200 \mu \mathrm{l}$ rabbit antithrombospondin antiserum (1:10,000 dilution in assay buffer (kindly donated by Drs N. Hunter and D. Pepper, Scottish National Blood Transfusion Service) and incubated overnight at $4^{\circ} \mathrm{C}$. Anti-rabbit secondary antibody $(300 \mu \mathrm{l})$ (Sac-cel, AA-SAC1) was added followed by 30-min incubation, addition of $3 \mathrm{ml}$ wash solution and centrifugation for $20 \mathrm{~min}$ at $1500 \mathrm{~g}$ and $8^{\circ} \mathrm{C}$. The precipitate containing the bound fraction was counted for $120 \mathrm{sec}$ on an LKB 1260 multiwell counter (Wallac, Milton Keynes, UK) and results calculated using a linear interpolation program of $\% \mathrm{~B} / \mathrm{B} 0$ versus $\log _{10}$ standard concentration (RiaCalc LM programme, Turku, Finland) (23).

Assessment of angiogenesis by CD31 immunostaining. Five- $\mu \mathrm{m}$ sections were cut from formalin-fixed, paraffin-embedded 
specimens of primary breast cancers. The specimens were de-waxed in xylene, followed by four changes of ethanol and washed in tap water prior to staining. Endogenous peroxidase activity was blocked with $3 \%$ hydrogen peroxide in deionized water for $10 \mathrm{~min}$. Tissue sections were put in citrate buffer $(\mathrm{pH} 6.0,0.1 \mathrm{M})$ and placed on a rotating table in a microwave. Heat pre-treatment was carried out in two cycles of $15 \mathrm{~min}$ each at medium high output $(600 \mathrm{~W})$. The sections were allowed to cool at room temperature and washed prior to immunostaining. Non-specific binding was blocked with $1 \%$ normal goat serum in TRIS buffered saline (TBS) for $10 \mathrm{~min}$. Serial sections were incubated with primary antibody (monoclonal antibody to CD31 1:20; JC70 Dako). The slides were washed with TBS and incubated with biotinylated secondary (1:100, Dako) antibody in $1 \%$ goat serum in TBS for $30 \mathrm{~min}$ followed by washing in TBS for $2-3 \mathrm{~min}$. The streptavidin biotin complex (1:100 in TBS; Dako Strept ABC complex, Denmark) was applied for 30 min and washed with TBS. The slides were treated with $0.08 \%$ diaminobenzidine (DAB, Sigma) and hydrogen peroxide $(0.3 \%)$ in deionized water, then counterstained with haematoxylin, dehydrated and mounted with DPX.

Microvessel count: assessment of angiogenesis. Microvessel density was quantified by light microscopy without knowledge of patient details. The most vascular areas in a tumour (hot-spots) were located at low magnification and the vessels were counted using a Chalkley point eyepiece graticule at magnification x400 (28). Any brown-staining EC or group of cells in contact with a spot in a graticule was counted as an individual vessel. The mean of four Chalkley counts for each tumour was calculated and used in statistical analysis. Microvessel density was assessed without knowledge of serum analyte levels.

Statistical analysis. The median (M) and inter-quartile range (IQR) was calculated for all sets of variables and all p-values were derived using the Mann Whitney $U$ test for non-parametric data. Correlations between variable data were calculated using the Spearmen correlation analysis. $\mathrm{P}<0.05$ was taken as the level of statistical significance.

\section{Results}

Histopathological analysis of the primary tumours revealed 35 women with lymph node metastases and 36 women with lymph node negative disease at the time of primary surgery. Bloom and Richardson classification of tumour grade demonstrated 16 women with grade 1 tumours, 20 with grade 2 tumours and 35 with grade 3 tumours. All the cancers analysed were invasive ductal carcinoma of no special type. Median tumour size was $21 \mathrm{~mm}$ [interquartile range (IQR) 12-27 mm].

Plasma TSP-1 levels in EBC (median $484 \mathrm{ng} / \mathrm{ml}$, IQR 344-877) were raised when compared to controls (median 221 ng/ml, IQR 175 - 247) (Fig. 1) (p<0.05). Plasma TSP-1 in high grade tumours (grades 2 and 3) were higher than in grade 1 tumours (median 343, IQR 294-428) ( $p<0.05$ ). Plasma TSP-1 was raised in women with lymph node metastases (median $799 \mathrm{ng} / \mathrm{ml}$, IQR 455-943) when compared to lymph node negative women (median $343 \mathrm{ng} / \mathrm{ml}$, IQR 267-514)

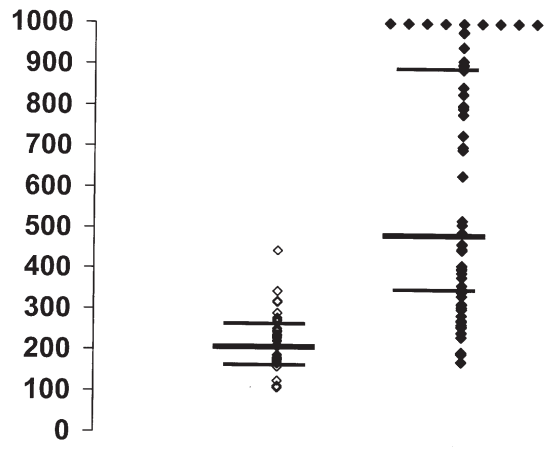

normal breast - early breast cancer

Figure 1. Plasma TSP-1 in early breast cancer compared to normal controls. Median levels of TSP-1 are higher in early breast cancer than in normal controls (error bars represent median levels and interquartile range).

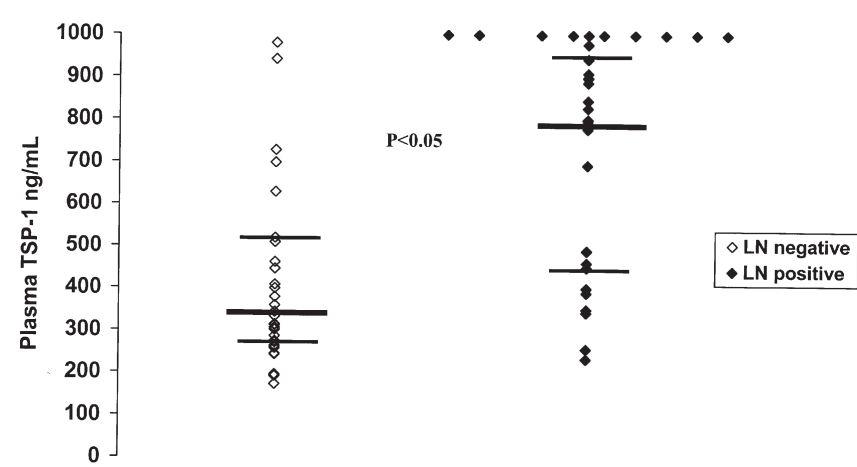

Figure 2. Plasma TSP-1 in lymph node negative and lymph node positive women with early breast cancer. Women with lymph node metastases have higher circulating levels of TSP-1 than women who do not.

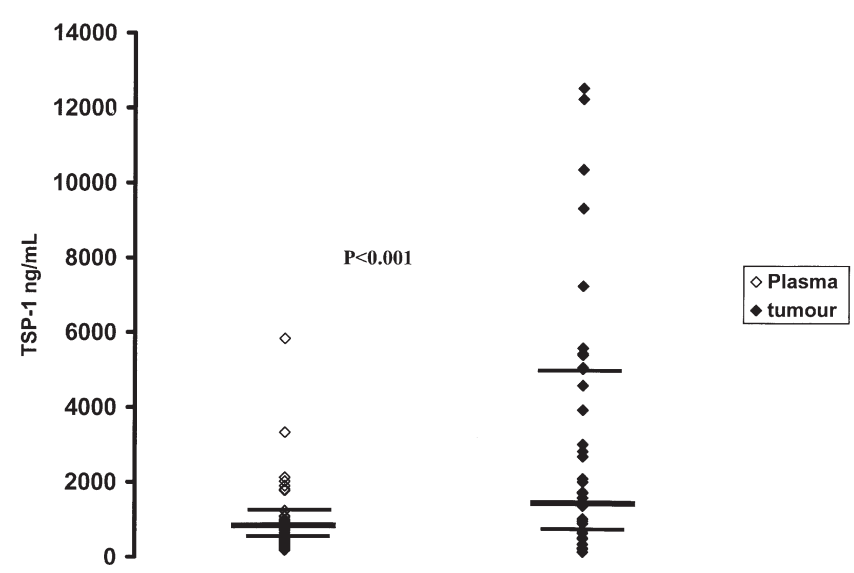

Figure 3. TSP-1 levels in plasma and tumour in women with early breast cancer. Median tumour TSP-1 concentrations were four times higher than those observed in plasma $(\mathrm{p}<0.001)$.

(Fig. 2). No correlation was observed between tumour size and plasma TSP-1 levels ( $\mathrm{R}=0.09)$.

Intratumoural thrombospondin was detected by RIA in all tumours assayed (median level $1714 \mathrm{ng} / \mathrm{ml}$, IQR 893-5283) (Fig. 3). Median levels were higher than median levels of TSP-1 in the cytosols of controls (median 623, IQR 561-1430, $\mathrm{p}<0.05)$. Intratumoural levels of TSP-1 correlated with plasma levels of TSP-1 ( $\mathrm{R}=0.64, \mathrm{p}<0.001)$ (Fig. 4). Plasma TSP-1 


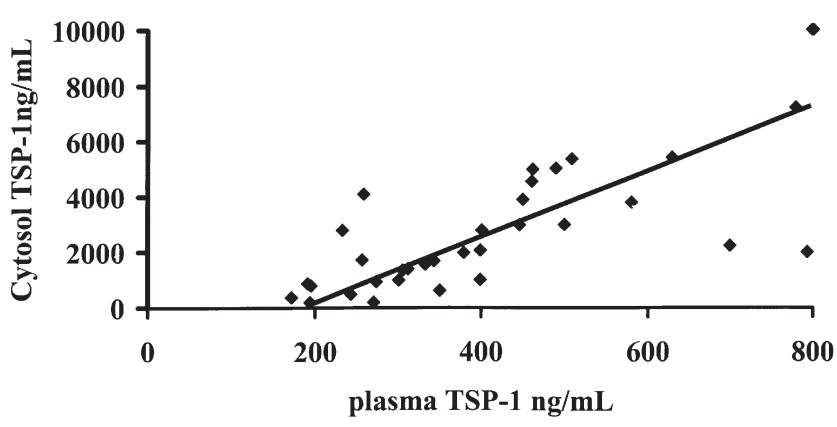

Figure 4. Levels of cytosol TSP-1 and plasma TSP-1 in women with breast cancer. A strong correlation was observed between intratumoural and circulating levels of TSP-1 $(\mathrm{R}=0.64, \mathrm{p}<0.001)$.

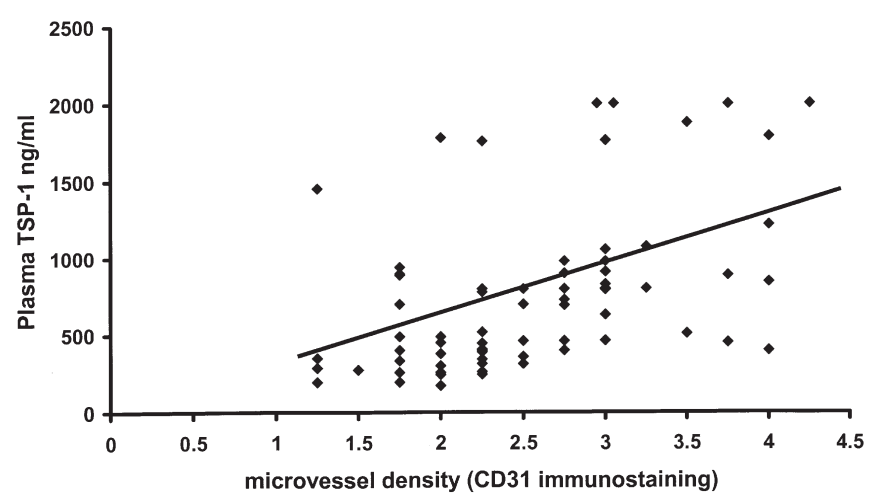

Figure 5. Levels of plasma TSP-1 compared to intratumoural microvessel density. A weak positive correlation was observed between intratumoural microvessel density and circulating thrombospondin suggesting an angiogenic rather than antiangiogenic association $(R=0.39, p<0.05)$.

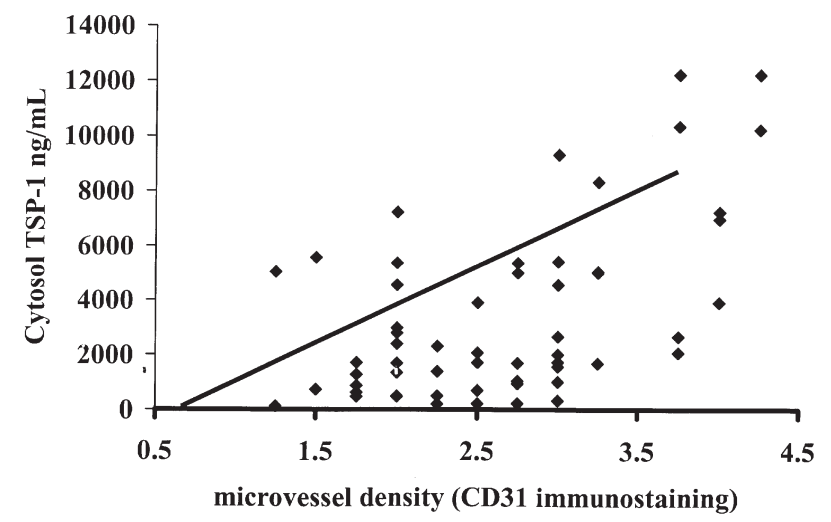

Figure 6. Levels of cytosol TSP-1 compared to intratumoural microvessel density. A positive correlation was observed between tumoural TSP-1 and angiogenesis $(\mathrm{R}=0.46, \mathrm{p}<0.01)$.

and intratumoural levels of TSP-1 correlated with microvessel density $(\mathrm{R}=0.39, \mathrm{p}<0.05$ and $\mathrm{R}=0.46, \mathrm{p}<0.01$ respectively) (Figs. 5 and 6). Levels of plasma TSP-1 in women with advanced breast cancer (median $588 \mathrm{ng} / \mathrm{ml}$, IQR 430-952) were raised when compared to controls.

\section{Discussion}

This study demonstrates a positive correlation between intratumoral and circulating levels of thrombosponsin- 1 with intratumoural microvessel density (IMD) suggesting an angiogenic rather than anti-angiogenic role for TSP-1 in women with early breast cancer. These data further suggest that raised circulating levels of TSP-1, measured in the absence of plasma contamination by platelet activation, are likely to be derived from the primary tumour rather than an unrelated source. Moreover, plasma levels of TSP-1 positively correlate with established clinicopathological prognostic parameters. Angiogenesis is essential for tumour growth and metastasis (29-31). TSP-1 has been implicated in the development of metastasis because it promotes tumour cell adhesion, motility and invasion in in vitro models $(32,33)$ and is overexpressed in several human solid tumours including breast cancer $(12,13)$. Because of conflicting in vitro and in vivo studies that explored the role of TSP-1 in tumoural angiogenesis, we have sought to clarify the relationship of TSP-1 to angiogenesis in human breast cancer.

This study confirms the finding of several previous immunohistochemical and in situ hybridisation studies that TSP-1 is overexpressed in breast cancer tissue when compared to normal breast tissue (12-14). One of the original descriptions of TSP-1, by Bouck and co-workers (15), was as an antiangiogenic product of a tumour suppressor gene. In this study, TSP-1 inhibited the BFGF-stimulated formation of angiogenic vessels in the rat corneal model. More recently, Ben-Ezra et al (17) reported a TSP-1-induced pro-angiogenic effect in association with BFGF in a similar model to that used by Bouck. The principal differences between these studies were the model used (Bouck-rat, Ben Ezra-rabbit) and the dose of TSP-1 applied in conjunction with BFGF (Bouck-0.125 $\mu \mathrm{g}$, Ben Ezra-0.5 $\mu \mathrm{g}$ ). Similarly, using a Boyden chamber cell migration assay, Taraboletti et al (7) demonstrated that, at concentrations of 5-50 $\mu \mathrm{g} / \mathrm{ml}$, TSP-1, with or without BFGF, stimulated endothelial cell motility. Conversely, using the same assay, but at a TSP-1 concentration of $2.5 \mu \mathrm{g} / \mathrm{ml}$, Tolsma et al (16) reported that TSP-1 inhibited BFGF endothelial cell migration.. Thus the effect of TSP-1 appears to be dose-dependent. Although we have not confirmed a causal relationship between TSP-1 and angiogenesis, the data demonstrate that TSP-1 levels in tumour and plasma in women with established early breast cancer positively correlate with the established method of measuring angiogenesis (immunostaining of the CD31 antigen in paraffin-embedded sections of tumour). We were unable to demonstrate any inverse relationship between angiogenesis and tumoural or plasma TSP-1 levels. It would thus appear that levels of TSP-1 in human early breast cancer are greater than those required for TSP-1 to have an anti-angiogenic effect. Thus, in early breast cancer, TSP-1 is likely to be angiogenic rather than anti-angiogenic.

Because TSP-1 is stored in large quantities in the $\alpha$ granules of platelets (1), several authors have reported difficulties in determining the contribution of non-platelet sources to circulating levels of TSP-1 (33-35). We have previously described a sensitive and precise radioimmunoassay for the measurement of TSP-1 in plasma (23). This study sought to 
define the relationship between circulating levels of TSP-1 and established clinicopathological characteristics (including intratumoural microvessel density) in women with breast cancer. In addition to demonstrating a direct correlation between plasma levels of TSP-1 and tumour stage, we have also shown a direct correlation between plasma levels of TSP-1 and cytosol levels of TSP-1. This finding supports the suggestions of others $(21,24,33)$ that the majority of nonplatelet-bound, circulating TSP-1 in malignant disease is derived from the tumour itself rather than any non-tumoral source.

Our data demonstrate a direct correlation between plasma levels of TSP-1 and breast cancer stage with highest levels of all being found in women with metastatic breast cancer. This observation is similar to the observation of Tuszynki and co-workers who demonstrated a correlation between plasma TSP-1 levels and stage in patients with lung and gastrointestinal malignancy (34). Thus, measurement of plasma levels of TSP-1 may have clinical value as a surrogate marker of stage and metastasis. This study is the first to demonstrate a correlation between plasma TSP-1 levels and IMD. Similar to cytosol TSP-1, levels of TSP-1 in plasma correlated positively with IMD suggesting a pro-angiogenic rather than an anti-angiogenic effect in breast cancer.

Current accepted methods for measuring angiogenesis in solid tumours require the immunostaining of sections of primary tumour using antibodies to endothelial-specific antigens such as CD31, CD34 and Von Willebrand Factor (35). Following immunostaining, intratumoural microvessel density (IMD) is assessed by counting blood vessels in a semiquantitative fashion using light microscopy $(36,37)$. Measurements of IMD have been shown to correlate with relapse-free and overall survival in patients with breast cancer (37-40).

\section{References}

1. Baenziger NL, Brodie GN and Majerus PW: A thrombinsensitive protein of human platelet membranes. Proc Natl Acad Sci USA 68: 240-243, 1971 .

2. Lawler $\mathbf{J}$ and Hynes RO: The structure of human thrombospondin, an adhesive glycoprotein with multiple calciumbinding sites and homologies with several different proteins. J Cell Biol 103: 1635-1648, 1986.

3. Dawes JCK and Gogstad L: A radioimmunoassay for thrombospondin used in a comparative study of thrombospondin, bthromboglobulin and platelet factor-4 in healthy volunteers. Thromb Res 29: 569-581, 1983.

4. Lawler J, Weinstein R and Hynes RO: Cell attachment to thrombospondin: the role of ARG-GLY-ASP, calcium, and integrin receptors. J Cell Biol 107: 2351-2361, 1988.

5. Dreyfus M and Lahav J: The build-up of the thrombospondin extracellular matrix. An apparent dependence on synthesis and on preformed fibrillar matrix. Eur J Cell Biol 47: 275-282, 1988.

6. Asch AS, Barnwell J, Silverstein RL and Nachman RL: Isolation of the thrombospondin membrane receptor. J Clin Invest 79: 1054-1061, 1987.

7. Taraboletti G, Roberts D, Liotta LA and Giavazzi R: Platelet thrombospondin modulates endothelial cell adhesion, motility, and growth: a potential angiogenesis regulatory factor. J Cell Biol 111: 765-772, 1990.

8. Boukerche H, Berthier-Vergnes O, Tabone E, Bailly M, Dore JF and McGregor JL: Thrombospondin modulates melanomaplatelet interactions and melanoma tumour cell growth in vivo. Br J Cancer 72: 108-116, 1995.

9. Wang TN, Qian XH, Granick MS, Solomon MP, Rothman VL and Tuszynski GP The effect of thrombospondin on oral squamous carcinoma cell invasion of collagen. Am J Surg 170: 502-505, 1995 .
10. Tuszynski GP, Gasic TB, Rothman VL, Knudsen KA and Gasic GJ: Thrombospondin, a potentiator of tumor cell metastasis. Cancer Res 47: 4130-4133, 1987.

11. Incardona F, Lewalle JM, Morandi V, Lambert S, Legrand Y, Foidart JM and Legrand C: Thrombospondin modulates human breast adenocarcinoma cell adhesion to human vascular endothelial cells. Cancer Res 55: 166-173, 1995.

12. Pratt DA, Miller WR and Dawes J: Thrombospondin in malignant and non-malignant breast tissue. Eur J Cancer Clin Oncol 25: 343-350, 1989.

13. Wong SY, Purdie AT and Han P: Thrombospondin and other possible related matrix proteins in malignant and benign breast disease. An immunohistochemical study. Am J Pathol 140: 1473-1482, 1992.

14. Clezardin P, Frappart L, Clerget M, Pechoux C and Delmas PD: Expression of thrombospondin (TSP1) and its receptors (CD36 and CD51) in normal, hyperplastic, and neoplastic human breast. Cancer Res 53: 1421-1430, 1993.

15. Good DJ, Polverini PJ, Rastinejad F, Le Beau MM, Lemons RS, Frazier WA and Bouck NP: A tumor suppressor-dependent inhibitor of angiogenesis is immunologically and functionally indistinguishable from a fragment of thrombospondin. Proc Natl Acad Sci USA 87: 6624-66288, 1990.

16. Tolsma SS, Volpert OV, Good DJ, Frazier WA, Polverini PJ and Bouck N: Peptides derived from two separate domains of the matrix protein thrombospondin-1 have anti-angiogenic activity. J Cell Biol 122: 497-511, 1993.

17. BenEzra D, Griffin BW, Maftzir G and Aharonov O: Thrombospondin and in vivo angiogenesis induced by basic fibroblast growth factor or lipopolysaccharide. Invest Ophthalmol Vis Sci 34: 3601-3608, 1993

18. Grossfeld GD, Ginsberg DA, Stein JP, Bochner BH, Esrig D, Groshen S, Dunn M, Nichols PW, Taylor CR, Skinner DG and Cote RJ: Thrombospondin-1 expression in bladder cancer: association with p53 alterations, tumor angiogenesis, and tumor progression. J Natl Cancer Inst 89: 219-227, 1997.

19. Agam G, Shohat O and Livne A: Thrombospondin plays a role in platelet-platelet recognition during release-related aggregation. Proc Soc Exp Biol Med 177: 482-486, 1984.

20. Switalska HI, Niewiarowski S, Tuszynski GP, Rucinski B, Schmaier AH, Morinelli TA and Cierniewski CS: Radioimmunoassay of human platelet thrombospondin: different patterns of thrombospondin and beta-thromboglobulin antigen secretion and clearance from the circulation. J Lab Clin Med 106: 690-700, 1985 .

21. Dawes J, Pratt DA, Dewar MS and Preston FE: Do extra-platelet sources contribute to the plasma level of thrombospondin? Thromb Haemost 59: 273-276, 1988.

22. Trzeciak MC, McGregor J, Renaux JL, Ville D, Berruyer M, Dawes J and Dechavanne M: Plasma thrombospondin in patients with chronic renal failure, liver disease and splenectomy. Thromb Res 40: 121-128, 1985.

23. Hayden K, Tetlow L, Byrne G and Bundred N: Radioimmunoassay for the measurement of thrombospondin in plasma and breast cyst fluid: validation and clinical application. Ann Clin Biochem 37: 319-325, 2000

24. Nathan FE, Hernandez E, Dunton CJ, Treat J, Switalska HI, Joseph RR and Tuszynski GP: Plasma thrombospondin levels in patients with gynecologic malignancies. Cancer 73: 2853-2858, 1994.

25. Yamashita Y, Kurohiji T, Tuszynski GP, Sakai T and Shirakusa T: Plasma thrombospondin levels in patients with colorectal carcinoma. Cancer 82: 632-638, 1998.

26. Ozatli D, Kocoglu H, Haznedaroglu IC, Kosar A, Buyukasik Y, Ozcebe O, Kirazli S and Dundar SV: Circulating thrombomodulin, thrombospondin, and fibronectin in acute myeloblastic leukemias. Haematologia (Budap) 29: 277-283, 1999.

27. Greenwood FC and Glover JS: The preparation of ${ }^{131}$ I-labeled human growth hormone of high specific radioactivity. Biochem J 89: 114-123, 1963.

28. Chalkley H: Method for quantitation morphological analysis of tissues. J Natl Cancer Inst 4: 47-53, 1943.

29. Fidler IJ and Ellis LM: The implications of angiogenesis for the biology and therapy of cancer metastasis. Cell 79: 185-188, 1994.

30. Bicknell R and Harris AL: Novel growth regulatory factors and tumour angiogenesis. Eur J Cancer 27: 781-785, 1991.

31. Folkman J: Angiogenesis in cancer, vascular, rheumatoid and other disease. Nat Med 1: 27-31, 1995. 
32. Riser BL, Varani JK and Dixit VM: Thrombospondin binding by human squamous carcinoma and melanoma cells: relationship to biological activity. Exp Cell Res 174: 319-329, 1988.

33. Qian X and Tuszynski GP: Expression of thrombospondin-1 in cancer: a role in tumor progression. Proc Soc Exp Biol Med 212: 199-207, 1996.

33. Yamashita Y, Kurohiji T, Tuszynski GP, Sakai T and Shirakusa T: Plasma thrombospondin levels in patients with colorectal carcinoma. Cancer 82: 632-638, 1998.

34. Tuszynski GP, Smith M, Rothman VL, Capuzzi DM, Joseph RR, Katz J, Besa EC, Treat J and Switalska HI: Thrombospondin levels in patients with malignancy. Thromb Haemost 67: 607-611, 1992.

35. Lane DA, Ireland H, Wolff S, Ranasinghe $\mathrm{E}$ and Dawes $\mathrm{J}$ : Detection of enhanced in vivo platelet alpha-granule release in different patient groups - comparison of beta-thromboglobulin, platelet factor 4 and thrombospondin assays. Thromb Haemost 52: 183-187, 1984.

35. Vermeulen PB, Gasparini G, Fox SB, Toi M, Martin L McCulloch P, Pezzella F, Viale G, Weidner N, Harris AL and Dirix LY: Quantification of angiogenesis in solid human tumours: an international consensus on the methodology and criteria of evaluation. Eur J Cancer 32A: 2474-2484, 1996.
36. Weidner N, Semple JP, Welch WR and Folkman J: Tumor angiogenesis and metastasis - correlation in invasive breast carcinoma. N Engl J Med 324: 1-8, 1991.

37. Kumar S, Ghellal A, Li C, Byrne G, Haboubi N, Wang JM and Bundred N: Breast carcinoma: vascular density determined using CD105 antibody correlates with tumor prognosis. Cancer Res 59: 856-861, 1999.

38. Horak ER, Leek R, Klenk N, Le Jeune S, Smith K, Stuart N, Greenall M, Stepniewska K and Harris AL: Angiogenesis, assessed by platelet/endothelial cell adhesion molecule antibodies, as indicator of node metastases and survival in breast cancer. Lancet 340: 1120-1124, 1992.

39. Weidner N, Folkman J, Pozza F, Bevilacqua P, Allred EN, Moore DH, Meli S and Gasparini G: Tumor angiogenesis: a new significant and independent prognostic indicator in earlystage breast carcinoma. J Natl Cancer Inst 84: 1875-1887, 1992.

40. Bevilacqua MP: Endothelial-leukocyte adhesion molecules. Ann Rev Immunol 11: 767-804, 1993. 